\title{
Co-existent Macro-prolactinoma, Raised Free T4 and Right Sided Facial Nerve Palsy
}

\author{
Gohil SG ${ }^{1}$, Levy MJ1 \\ Department of Endocrinology, University Hospitals of Leicester NHS Trust, Leicester, LE1 5WW
}

\section{Case:}

- 47 year old $O^{7}$

- 3 day history of headache and vomiting

- Right facial paraesthesia and droop

- No 'endocrine' symptoms

\section{Investigations:}

- $\mathrm{CT}$ head: $4.7 \times 3.3 \times 3.9 \mathrm{~cm}$ enhancing lesion extending superiorly from the pituitary. Appearances are in keeping with a pituitary macroadenoma. Opacification of the right middle ear and mastoid air cells. Mass compressing facial nerve in the facial canal.

\begin{tabular}{|llc|}
\hline \multicolumn{1}{|c|}{ 9am bloods } & \multicolumn{1}{c|}{ Value } & Reference \\
Prolactin & $95570 \mathrm{miu} / \mathrm{L}$ & $50-400$ \\
LH & $1 \mathrm{iu} / \mathrm{L}$ & $1-9$ \\
FSH & $1.1 \mathrm{iu} / \mathrm{L}$ & $1-10$ \\
Testosterone & $0.8 \mathrm{nmol} / \mathrm{L}$ & $9.4-37$ \\
TSH & $3.2 \mathrm{miu} / \mathrm{L}$ & $0.3-5$ \\
fT4 & $118.9 \mathrm{pmol} / \mathrm{L}$ & $9-25$ \\
Cortisol & $428 \mathrm{nmol} / \mathrm{L}$ & \\
\hline
\end{tabular}

Above: Blood test results. Below: Middle ear mass ?glomus tumour
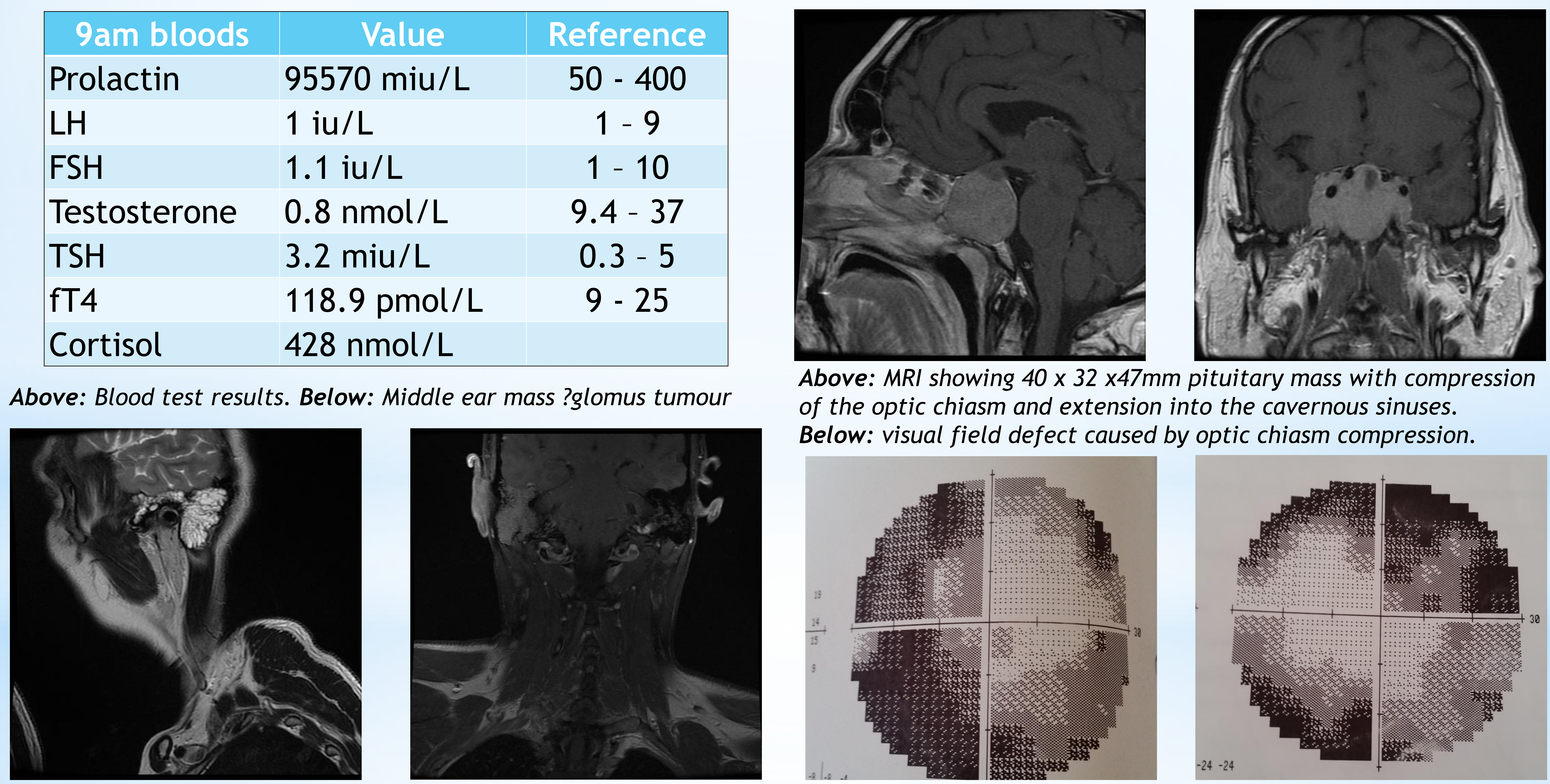

Above: MRI showing $40 \times 32 \times 47 \mathrm{~mm}$ pituitary mass with compression of the optic chiasm and extension into the cavernous sinuses.

Below: visual field defect caused by optic chiasm compression.
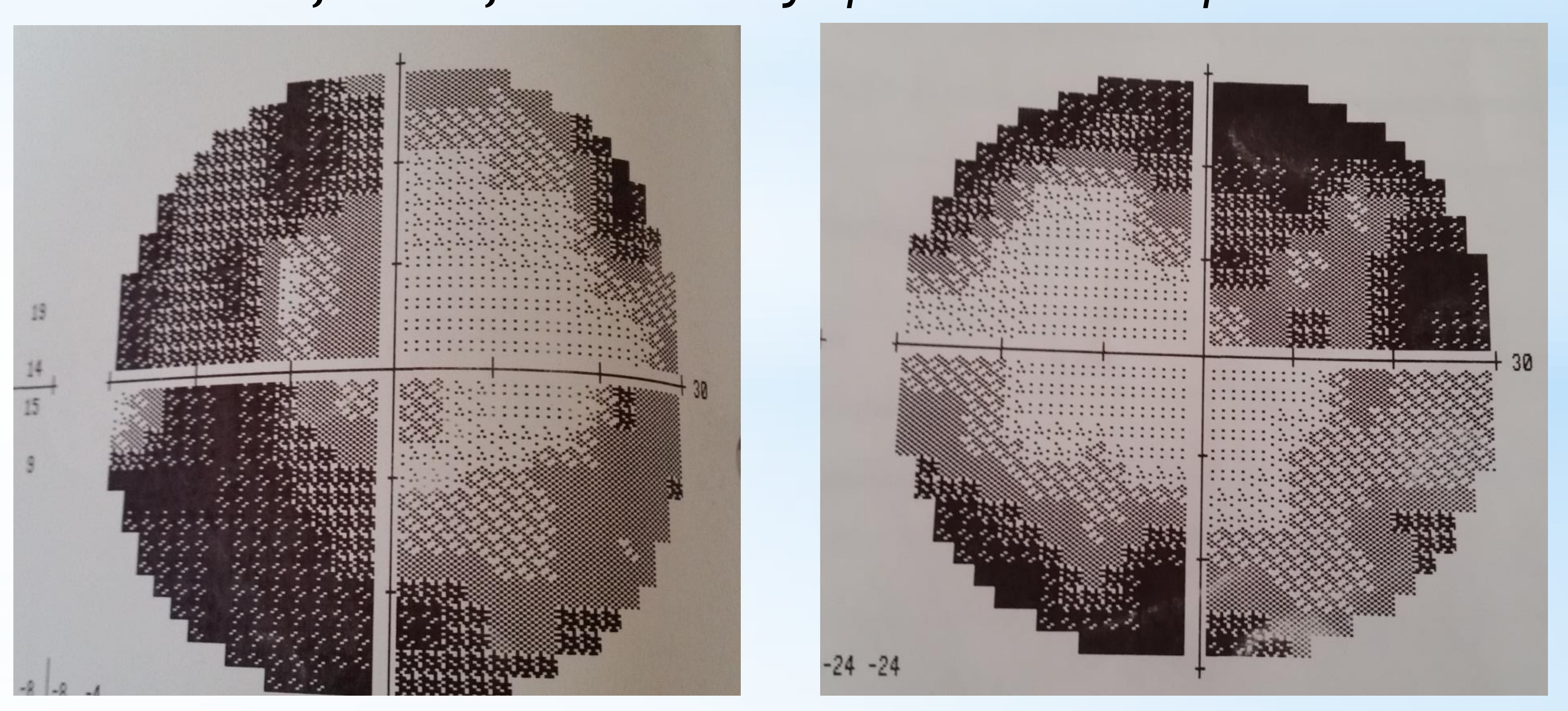

\section{Discussion:}

- Macroprolactinoma - started cabergoline

- Possibility of co-secretion of TSH but no thyrotoxic symptoms - what can the cause of these results be?

- What about the low testosterone?

- What is the link between the middle ear glomus tumour and pituitary mass?

Artificially raised fT4



Artificially raised fT4

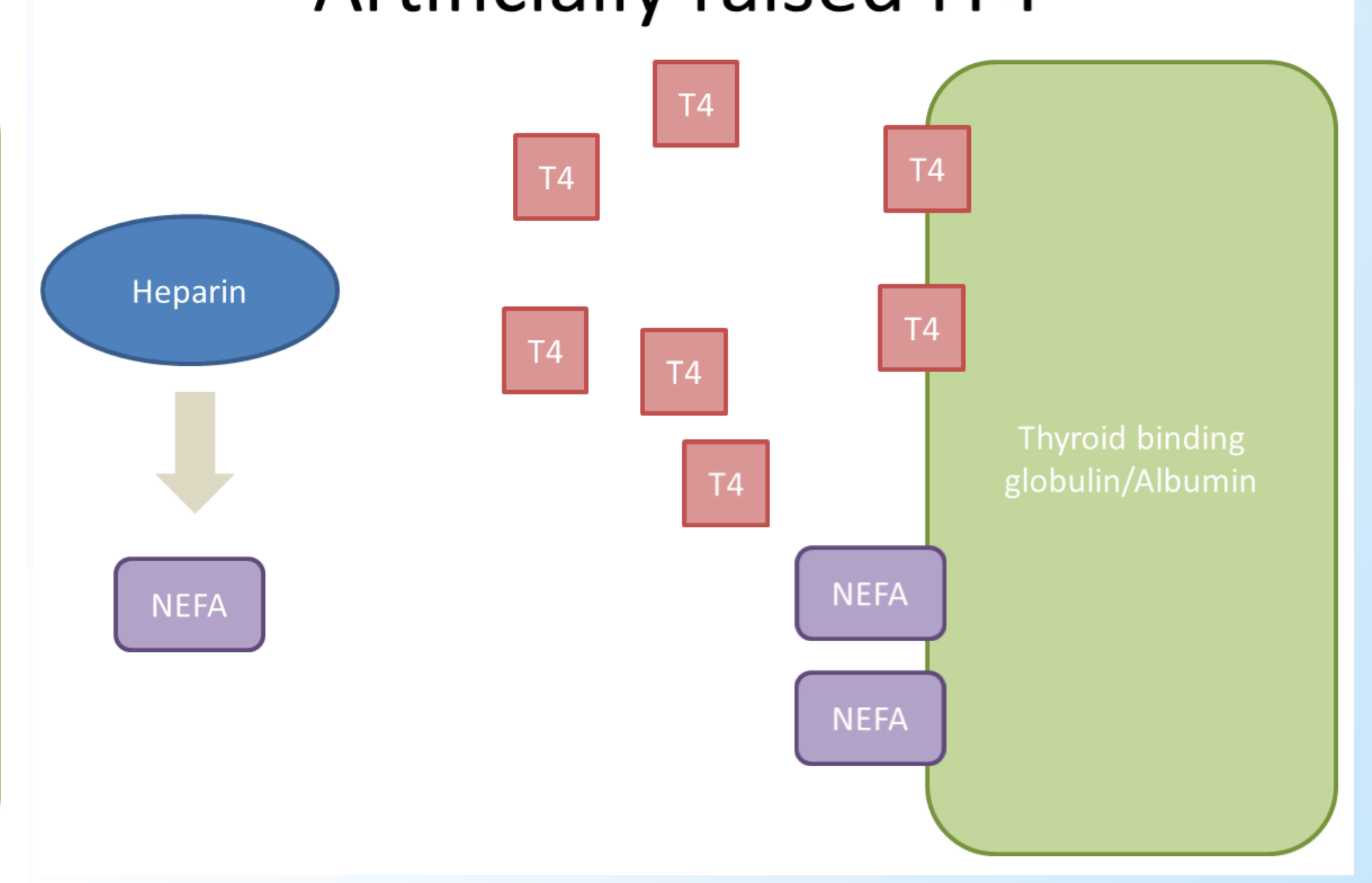

\section{Conclusion:}

- The tumour was not co-secreting TSH. Most patients get low molecular weight heparin as an inpatient and this interferes with the assay by activating endothelial lipoprotein lipase producing non-esterified fatty acids. This competes with the biding site for T4 on TBG/albumin during the assay creating a falsely raised fT4. Get around this by using another assay or re-checking TFTs once off heparin.

- Low testosterone will improve once prolactin reduces. No need to treat low testosterone

- Link between glomus tumour and pituitary tumour could be succinate dehydrogenase gene mutation. Currently begin investigated by the Ear, Nose and Throat team. 